\title{
The brown fat-secreted adipokine neuregulin 4 is decreased in human and murine chronic kidney disease
}

\author{
Susan Kralisch ${ }^{1,2}$, Annett Hoffmann', Nora Klöting' ${ }^{2}$, Armin Frille ${ }^{2,3}$, Hartmut Kuhn ${ }^{3}$, Marcin Nowicki ${ }^{4}$, \\ Sabine Paeschke, Anette Bachmann', Matthias Blüher', Ming-Zhi Zhang, ${ }^{5,6}$, Raymond C Harris ${ }^{5,6}$, \\ Michael Stumvoll', Mathias Fasshauer ${ }^{1,2,7}$ and Thomas Ebert 1,2,8
}

${ }^{1}$ Medical Department III - Endocrinology, Nephrology, Rheumatology, University of Leipzig Medical Center, ${ }^{2}$ Leipzig University Medical Center, IFB AdiposityDiseases, ${ }^{3}$ Department of Respiratory Medicine, University of Leipzig, ${ }^{4}$ University of Leipzig, Institute of Anatomy, Leipzig, Germany, ${ }^{5}$ Division of Nephrology, Department of Medicine, ${ }^{6}$ Department of Medicine, Nashville Veterans Affairs Hospital, Vanderbilt University School of Medicine, Nashville, Tennessee, USA, ${ }^{7}$ Justus-Liebig-University, Institute of Nutritional Science, Giessen, Germany, and ${ }^{8}$ Division of Renal Medicine, Department of Clinical Science, Intervention and Technology, Karolinska Institutet, Stockholm, Sweden

Correspondence should be addressed to T Ebert

Email

Thomas.ebert@medizin. uni-leipzig.de

\begin{abstract}
Objective: Neuregulin 4 (NRG4) has recently been introduced as a novel brown adipose tissue (BAT)-secreted adipokine with beneficial metabolic effects in mice. However, regulation of Nrg4 in end-stage kidney disease (ESKD) and type 2 diabetes mellitus (T2DM) has not been elucidated, so far.

Design/methods: Serum NRG4 levels were quantified by ELISA in 60 subjects with ESKD on chronic hemodialysis as compared to 60 subjects with an estimated glomerular filtration rate $>50 \mathrm{~mL} / \mathrm{min} / 1.73 \mathrm{~m}^{2}$ in a cross-sectional cohort. Within both groups, about half of the patients had a T2DM. Furthermore, mRNA expression of Nrg4 was determined in two mouse models of diabetic kidney disease (DKD) as compared to two different groups of non-diabetic control mice. Moreover, mRNA expression of Nrg4 was investigated in cultured, differentiated mouse brown and white adipocytes, as well as hepatocytes, after treatment with the uremic toxin indoxyl sulfate.

Results: Median serum NRG4 was significantly lower in patients with ESKD compared to controls and the adipokine was independently associated with a beneficial renal, glucose and lipid profile. In mice with DKD, Nrg4 mRNA expression was decreased in all adipose tissue depots compared to control mice. The uremic toxin indoxyl sulfate did not significantly alter $\mathrm{Nrg} 4 \mathrm{mRNA}$ expression in adipocytes and hepatocytes, in vitro.

Conclusions: Circulating NRG4 is independently associated with a preserved renal function and mRNA expression of -Nrg4 is reduced in adipose tissue depots of mice with DKD. The BAT-secreted adipokine is further associated with a beneficial glucose and lipid profile supporting NRG4 as potential treatment target in metabolic and renal disease states.
\end{abstract}

\section{Introduction}

The prevalence of diabetes mellitus and chronic kidney disease (CKD) is increasing and results in a rise of death rates for these diseases (1). Besides diabetes mellitus and hypertension as cardiometabolic disease states, obesity has also been shown to be an independent risk factor for a decline in renal function and death in a recent (c) 2019 European Society of Endocrinology Printed in Great Britain meta-analysis (2). Thus, patients with a BMI of $40 \mathrm{~kg} / \mathrm{m}^{2}$ had a hazard ratio of 2.02 for an estimated glomerular filtration rate (eGFR) decline as compared to subjects with a BMI of $25 \mathrm{~kg} / \mathrm{m}^{2}$ (2). Conversely, Shulman and coworkers demonstrate a long-term protection against end-stage kidney disease (ESKD) after bariatric surgery-induced

Published by Bioscientifica Ltd. 
weight loss as compared to control patients in the Swedish Obese Subjects (SOS) study (3). Thus, circulating adipose tissue-secreted factors, so-called adipokines, potentially could mediate the association between obesity and CKD.

During the last years, brown adipose tissue (BAT) has emerged as a major factor contributing to weight homeostasis and several BAT-secreted cytokines have been introduced as brown adipokines/batokines and potential pharmacological targets $(4,5)$.

Neuregulin 4 (NRG4) is a novel and predominantly BAT-secreted adipokine which protects against dietinduced insulin resistance and hepatic steatosis in mice (6). In more detail, Wang and coworkers demonstrate that Nrg4-deficient mice have increased insulin resistance and hepatic steatosis after high-fat diet feeding (6). Conversely, when mice with a transgenic overexpression of NRG4 are exposed to high-fat diet, they have an improved metabolic status, that is less body weight gain, improved dyslipidemia and insulin sensitivity, as compared to controls (6). Based on these data, NRG4 appears to be a novel brown adipokine with beneficial effects on obesity and its metabolic complications.

However, the regulation of circulating NRG4 in patients with CKD is far from clear and the role of NRG4 as a potentially protective factor for the development of ESKD has not been investigated, so far. Furthermore, NRG4 regulation in ESKD due to severe diabetic kidney disease (DKD) has to be compared to non-diabetic ESKD causes addressing a potential elimination of the novel brown adipokine.

Therefore, we quantified circulating NRG4 concentrations in 60 patients with ESKD on maintenance renal replacement therapy (RRT) treatment as compared to 60 subjects with an eGFR $>50 \mathrm{~mL} / \mathrm{min} / 1.73 \mathrm{~m}^{2}$. In both groups, about half of the patients had a type 2 diabetes mellitus (T2DM). Furthermore, the beneficial BAT-secreted adipokine was correlated with other markers of BAT function. Moreover, we investigated differential mRNA expression of $\mathrm{Nrg} 4$ in two mouse models of DKD, that is, $e \mathrm{NOS}^{-/-} ; d b / d b$ mice and $d b / d b$ mice on a C57BLKS background, as compared to two different groups of non-diabetic control mice. Finally, mRNA expression of $\mathrm{Nrg} 4$ was investigated in cultured, differentiated murine brown and white adipocytes, as well as in hepatocytes, after treatment with the uremic toxin indoxyl sulfate as compared to control treatment.

Our hypothesis was that the metabolically beneficial BAT-secreted adipokine is decreased in DKD and can serve as a potential treatment target in metabolic and renal disease states.

\section{Methods}

\section{Subjects}

The design of this cross-sectional study has been described previously $(7,8,9,10)$. Briefly, about 120 Caucasian subjects (women: $n=58$; men: $n=62$ ) were recruited by the Department of Endocrinology and Nephrology, University of Leipzig, from 2005 and 2007. Of the total cohort $(n=120)$, about half $(n=60)$ had an ESKD and were on maintenance RRT by hemodialysis. Study participants without CKD $(n=60)$ had an eGFR $>50 \mathrm{~mL} / \mathrm{min} / 1.73 \mathrm{~m}^{2}$ according to the Chronic Kidney Disease Epidemiology Collaboration (CKD-EPI) equation (11) and, therefore, were coded as controls. In all participants, past medical history and anthropometric data were obtained by trained staff of the Department of Endocrinology and Nephrology, University of Leipzig. A T2DM was defined as a fasting glucose (FG) $\geq 126 \mathrm{mg} / \mathrm{dL}$ or use of insulin or oral hypoglycemic medications (12). Using these criteria, 32 of the 60 patients with ESKD on RRT and 30 out of 60 control patients were coded as T2DM. Homeostasis model assessment of insulin resistance (HOMA-IR) was calculated as previously described (13). The following inclusion and exclusion criteria were applied for the present study: Inclusion criteria are age $>18$ years, nonpregnant, provided written informed consent; exclusion criteria: end-stage malignant diseases, acute generalized inflammation, acute infectious disease and history of drug abuse. The study was approved by the Ethics Committee of the University of Leipzig and all subjects gave written informed consent before taking part in the study.

\section{Animal study}

To determine NRG4 regulation in more detail, two animal models of CKD due to DKD on a C57BLKS background were compared to two groups of non-diabetic control mice. Thus, $e \mathrm{NOS}^{-/-} ; d b / d b$ mice served as a model for severe DKD (14), whereas $d b / d b$ mice were used as a model for mild DKD (15). Non-diabetic control animals included $\mathrm{eNOS}^{-/-}$mice, as well as $d b /+$ mice on a C57BLKS background. All animal experiments were performed in the Medical Experimental Center at the University of Leipzig as described previously $(10,16,17)$. All animal experiments were approved by the Local Ethics Committee of the State of Saxony (Landesdirektion Leipzig; approval nos. TVV 12/14 and TVV 65/15). Briefly, mice were maintained under pathogen-free conditions at $21 \pm 1^{\circ} \mathrm{C}$ on a 12 -h light/darkness cycle (6:00 h-18:00h). All animals had free access to water and a normal pellet 
diet. Spot urine was collected from all the mice in the morning at the age of 24 weeks. Afterward, the mice were killed by exsanguination under deep anesthesia with ketamine (WDT, Garbsen, Germany) and xylazine (Bayer Health Care, Wuppertal, Germany). Portions of the liver, kidney, as well as visceral (VAT), subcutaneous (SAT) and brown (BAT) adipose tissue, were snap-frozen in liquid nitrogen for RNA and protein isolation.

\section{Assays}

In human subjects, all blood samples were taken after a fasting period of at least $8 \mathrm{~h}$. In all ESKD patients, blood was obtained just before hemodialysis started. Serum levels of NRG4 (Phoenix Pharmaceuticals, Burlingame, CA, USA) were quantified using an ELISA according to the manufacturer's instructions. All other adipokines were quantified by ELISAs as described previously (7, 8, 9, 18). Routine serum parameters including creatinine, FG, fasting insulin (FI), triglycerides (TG), total, high-density lipoprotein (HDL) and low-density lipoprotein (LDL) cholesterol, as well as free fatty acids (FFA) were measured in a certified laboratory by standard methods.

In animal experiments, urinary albumin and creatinine were determined in spot urine using Albuwell $\mathrm{M}$ and Creatinine Companion kits (Exocell, Philadelphia, PA, USA) and albumin-creatinine ratios (ACR) were calculated, respectively.

\section{Effect of the uremic toxin indoxyl sulfate on $\mathrm{Nrg} 4$ mRNA expression in murine brown and white adipocytes, as well as hepatocytes, in vitro}

Briefly, immortalized brown preadipocytes (19), 3T3-L1 cells (American Type Culture Collection) and AML12 cells (American Type Culture Collection) were grown as previously described (brown adipocytes: (19), 3T3L1 white adipocytes: (7), AML12 hepatocytes: (17)). According to Stockler-Pinto and coworkers (20), after starvation, $1 \mathrm{mM}$ indoxyl sulfate was added for a period of $24 \mathrm{~h}$ to brown and white adipocytes, whereas AML12 hepatocytes were treated with $0.5 \mathrm{mM}$ indoxyl sulfate for $24 \mathrm{~h}$. The experiments were performed according to the recommendations of the European Uremic Toxin Work Group (EUTox) (21) and control cells were treated with $1 \mathrm{mM}$ or $0.5 \mathrm{mM}$ potassium sulfate (Sigma), respectively.

\section{Analysis of Nrg4 and Erbb4 mRNA production}

In animal and in in vitro experiments, $\mathrm{Nrg} 4$ and Erbb 4 mRNA expression was determined relative to acidic ribosomal phosphoprotein P0 (36B4 (RplpO)) using quantitative realtime RT-PCR. One microliter cDNA was quantified on a LightCycler 480 real-time PCR 96-well thermocycler using LightCycler 480 Probes Master Mix (Roche Diagnostics $\mathrm{GmbH}$ ) essentially as described in (7). The following primer pairs were used: Nrg4, CACTTGTGAAACGCTGCATGT and GGCAAAATGACCTGTGCCTG (antisense); Erbb4, CATGGACCGGGACCTGACAA (sense) and GGTAAAGT GGAATGGCCCGT (antisense); 36B4, AAGCGCGTCCTG GCATTGTCT (sense) and CCGCAGGGGCAGCAGTGGT (antisense).

\section{Statistical analysis}

SPSS software version 24.0 (IBM) was used for all statistical analyses of human data. Overall, group differences between the four subgroups (Control/T2DM-; Control/ T2DM+; RRT/T2DM-; RRT/T2DM+) were assessed by non-parametric Kruskal-Wallis test with Bonferroni post $h o c$ analysis for continuous parameters and $\chi^{2}$ test for categorical parameters. Afterward, linear regression models with adjustment for age, sex and BMI were calculated for all parameters. Before performing multivariate linear regression analyses, all continuous parameters were logarithmically transformed. Univariate correlations of other BAT-related adipokines with NRG4 were analyzed by non-parametric Spearman's rank correlation method.

For animal and in vitro experiments, GraphPad Prism 6 (GraphPad Software Inc.) was used. Relative Nrg4 and Erbb4 mRNA expression in different tissues adjusted for $36 B 4$, as well as ACR, were analyzed in mice with DKD, that is $e \mathrm{NOS}^{-/-} ; d b / d b$ mice and $d b / d b$ mice and were compared to control mice, that is $e \mathrm{NOS}^{-/-}$and $d b /+$ mice. Results for animal and in vitro experiments are shown as mean \pm s.D. All parameters were logarithmically transformed prior analyses. Group differences in the animal and in vitro experiments were analyzed by one-way ANOVA with Tukey's multiple comparisons test, as well as by Student's $t$ test, respectively

A $P$ value of $<0.05$ was considered as statistically significant in all analyses.

\section{Results}

\section{Baseline characteristics of the human cohort $(n=120)$}

Basic clinical characteristics of the study population divided into the four subgroups (i.e. Control/T2DM-; Control/T2DM+; RRT/T2DM-; RRT/T2DM+) are shown 
in Table 1. Median (interquartile range) serum NRG4 levels were $2.3(0.7) \mu \mathrm{g} / \mathrm{L}$ in the total sample. In the total cohort, circulating NRG4 was significantly higher in female $(2.3(0.7) \mu \mathrm{g} / \mathrm{L})$ as compared to male $(2.1(0.6) \mu \mathrm{g} / \mathrm{L})$ subjects $(P=0.026)$. In contrast, patients with T2DM (2.1 (0.8) $\mu \mathrm{g} / \mathrm{L})$ did not have different serum concentrations of the adipokine as compared to non-diabetic subjects $(2.3(0.7) \mu \mathrm{g} / \mathrm{L})(P=0.059)$.

When patients were stratified by the four subgroups, that is, Control/T2DM-; Control/T2DM+; RRT/T2DM-; RRT/T2DM+, circulating NRG4 was significantly different between the four subgroups $(P=0.010)$ (Table 1$)$.

\section{Association of NRG4 with metabolic parameters in the total cohort $(n=120)$}

Linear regression analysis revealed that serum concentrations of NRG4 remained independently and negatively associated with FI, HOMA-IR, TG and creatinine (all $P<0.05$; Table 2) after adjustment for age, sex and BMI. There was a significant, independent and positive association between NRG4 and systolic blood pressure, HDL cholesterol and eGFR (all $P<0.05$; Table 2). In contrast, the BAT-secreted adipokine was not independently associated with markers of obesity, LDL cholesterol, FFA and inflammation (Table 2). After excluding patients on metformin treatment, the associations between NRG4 and FI, HOMA-IR, TG, HDL cholesterol and renal function remained significant (data not shown).

\section{Correlation of NRG4 with other BAT-secreted adipokines and markers of BAT function in the total cohort $(n=120)$}

In the total cohort, NRG4 serum levels were positively correlated to irisin $(P=0.004)$ and adiponectin levels $(P=0.016)$ (Table 3$)$. Furthermore, NRG4 was negatively

Table 1 Baseline characteristics of the study population. Baseline characteristics of the study population stratified by the four subgroups, i.e. Control/T2DM-, Control/T2DM+, RRT/T2DM- and RRT/T2DM+. Values for median (interquartile range) or total numbers (percentage) are shown. Categorical parameters were analyzed using the $\chi^{2}$ test. Continuous parameters were analyzed by Kruskal-Wallis test followed by Bonferroni post hoc analysis. Overall $P$ values of the Kruskal-Wallis test are shown and significant $P$ values $(<0.05)$ are depicted in boldd.

\begin{tabular}{l}
\hline \\
\hline$n$ \\
Sex $(\mathrm{m} / \mathrm{f})$ \\
Nrg4 $(\mu \mathrm{g} / \mathrm{L})$ \\
Age $($ years $)$ \\
BMI $\left(\mathrm{kg} / \mathrm{m}^{2}\right)$ \\
WHR \\
WHtR \\
SBP $(\mathrm{mmHg})$ \\
DBP $(\mathrm{mmHg})$ \\
FG (mmol/L) \\
FI (pmol/L) \\
HOMA-IR \\
Cholesterol (mmol/L) \\
HDL cholesterol (mmol/L) \\
LDL cholesterol (mmol/L) \\
TG (mmol/L) \\
FFA (mmol/L) \\
Creatinine $(\mu \mathrm{mol} / \mathrm{L})$ \\
eGFR (mL/min/1.73 m²) \\
hsIL-6 (ng/L) \\
Leptin $(\mu g / L)$ \\
Metformin treatment $(\%)$
\end{tabular}

\begin{tabular}{c}
\hline Control/T2DM- \\
\hline 30 \\
$11 / 19$ \\
$2.5(0.7)^{\star}$ \\
$63(19)$ \\
$28.2(5.6)$ \\
$0.88(0.12)^{\S}$ \\
$0.57(0.08)^{\S}$ \\
$125(21)$ \\
$77(10)$ \\
$5.1(1.3)^{\ddagger}$ \\
$45.1(33.3)$ \\
$1.4(1.2)$ \\
$5.3(0.9)^{*, \S}$ \\
$1.4(0.4)^{*, \S}$ \\
$3.5(1.1)^{*, \neq, \S}$ \\
$1.1(0.8)^{*, \S}$ \\
$0.5(0.2)$ \\
$76(17)^{*, \S}$ \\
$78.8(24.4)^{*}, \S$ \\
$1.87(2.11)^{\star}, \S$ \\
$17.8(25.4)$ \\
$0(0)$
\end{tabular}

\begin{tabular}{c}
\hline Control/T2DM+ \\
\hline 30 \\
$16 / 14$ \\
$2.1(1.0)$ \\
$63(16)$ \\
$29.1(5.2)^{*}$
\end{tabular}

\begin{tabular}{c}
\hline RRT/T2DM- \\
\hline 28 \\
$15 / 13$ \\
$2.2(0.2)^{\dagger}$ \\
$59(23)$ \\
$25.2(6.5)^{\ddagger}$ \\
$0.96(0.18)$ \\
$0.57(0.16)$ \\
$125(38)$ \\
$77(20)$ \\
$4.6(1.2)^{\ddagger}$ \\
$28.2(47.6)$ \\
$0.8(1.4)^{\ddagger}$ \\
$4.4(1.1)^{\dagger}$ \\
$1.0(0.5)^{\dagger}$ \\
$2.7(0.9)^{\dagger}$ \\
$1.6(0.9)^{\dagger}$ \\
$0.6(0.5)$ \\
$829(431)^{\dagger, \ddagger}$ \\
$5.0(3.2)^{\dagger, \ddagger}$ \\
$6.14(4.91)^{\dagger, \ddagger}$ \\
$11.4(35.1)$ \\
$0(0)$
\end{tabular}

\begin{tabular}{cccc}
\hline RRT/T2DM+ & & Overall P \\
\cline { 1 - 1 } $20 / 12$ & & & 0.239 \\
$2.1(0.8)$ & & $\mathbf{0 . 0 1 0}$ \\
$68(12)$ & & 0.051 \\
$27.9(6.6)$ & & $\mathbf{0 . 0 0 4}$ \\
$1.00(0.14)^{\dagger}$ & & $<\mathbf{0 . 0 0 1}$ \\
$0.66(0.11)^{\dagger, \ddagger}$ & & $\mathbf{0 . 0 0 6}$ \\
$120(25)$ & & 0.339 \\
$70(18)$ & & 0.095 \\
$5.2(3.3)^{\ddagger}$ & & $<\mathbf{0 . 0 0 1}$ \\
$50.1(91.6)$ & & 0.230 \\
$1.4(3.3)$ & & $\mathbf{0 . 0 0 3}$ \\
$4.2(1.3)^{\dagger}$ & & $<\mathbf{0 . 0 0 1}$ \\
$1.0(0.3)^{\dagger, \ddagger}$ & & $<\mathbf{0 . 0 0 1}$ \\
$2.1(1.4)^{\dagger}$ & & $<\mathbf{0 . 0 0 1}$ \\
$1.8(1.4)^{\dagger}$ & & $<\mathbf{0 . 0 0 1}$ \\
$0.7(0.5)$ & & 0.173 \\
$717(221)^{\dagger, \ddagger}$ & & $<\mathbf{0 . 0 0 1}$ \\
$5.7(2.7)^{\dagger, \ddagger}$ & & $<\mathbf{0 . 0 0 1}$ \\
$7.48(7.30)^{\dagger, \ddagger}$ & & $<\mathbf{0 . 0 0 1}$ \\
$28.0(54.4)$ & & 0.065 \\
$0(0)$ & & $<\mathbf{0 . 0 0 1}$ \\
& &
\end{tabular}

Superscript numbers $(*, t, \ddagger$ §) indicate subgroup comparisons with Bonferroni post hoc analysis.

${ }^{*},+, \neq, \S$ Indicates $P<0.05$ as compared to *RRT/T2DM-, ${ }^{\dagger}$ Control/T2DM-, ${ }^{\ddagger}$ Control/T2DM+, and ${ }^{\S} \mathrm{RRT} / \mathrm{T} 2 \mathrm{DM}+$, respectively.

BMI, body mass index; DBP, diastolic blood pressure; eGFR, estimated glomerular filtration rate; FFA, free fatty acids; Fl, fasting insulin; HDL, high-density lipoprotein; HOMA-IR, homeostasis model assessment of insulin resistance; hsIL-6, high-sensitivity interleukin-6; LDL, low-density lipoprotein; RRT, maintenance renal replacement therapy; SBP, systolic blood pressure; T2DM, type 2 diabetes mellitus; TG, triglycerides; WHR, waist-to-hip ratio; WHtR, waist-to-height ratio. 
Table 2 Association of serum neuregulin 4 concentrations with anthropometric parameters and markers of glucose metabolism, serum lipids, inflammation and renal function. Associations were assessed in linear regression models adjusted for age, sex and BMI, respectively. All parameters were logarithmically transformed prior to analyses. Standardized $\beta$-coefficients and $P$ values are given.

\begin{tabular}{|c|c|c|}
\hline & $\boldsymbol{\beta}$ & $\boldsymbol{P}$ \\
\hline Age (years) & - & n.s. \\
\hline $\mathrm{BMI}\left(\mathrm{kg} / \mathrm{m}^{2}\right)$ & - & n.s. \\
\hline WHR & - & n.s. \\
\hline WHtR & - & n.s. \\
\hline SBP (mmHg) & 0.203 & 0.030 \\
\hline $\mathrm{DBP}(\mathrm{mmHg})$ & - & n.s. \\
\hline $\mathrm{FG}(\mathrm{mmol} / \mathrm{L})$ & - & n.s. \\
\hline $\mathrm{Fl}(\mathrm{pmol} / \mathrm{L})$ & -0.240 & 0.013 \\
\hline HOMA-IR & -0.222 & 0.021 \\
\hline Cholesterol (mmol/L) & - & n.s. \\
\hline HDL cholesterol (mmol/L) & 0.441 & $<0.001$ \\
\hline LDL cholesterol (mmol/L) & - & n.s. \\
\hline $\mathrm{TG}(\mathrm{mmol} / \mathrm{L})$ & -0.452 & $<0.001$ \\
\hline $\mathrm{FFA}(\mathrm{mmol} / \mathrm{L})$ & - & n.s. \\
\hline Creatinine $(\mu \mathrm{mol} / \mathrm{L})$ & -0.276 & 0.004 \\
\hline eGFR $\left(\mathrm{mL} / \mathrm{min} / 1.73 \mathrm{~m}^{2}\right)$ & 0.277 & 0.003 \\
\hline hsIL-6 (ng/L) & - & n.s. \\
\hline Leptin ( $\mu \mathrm{g} / \mathrm{L})$ & - & n.s. \\
\hline
\end{tabular}

n.s., non-significant model.

related to fibroblast growth factor 21 (FGF21) $(P=0.003)$ (Table 3). In contrast, there was no significant correlation between angiopoietin-like protein 8 and NRG4 (Table 3).

\section{Nrg4 and Erbb4 mRNA expression in mice with DKD}

Figure 1 summarizes animal data on NRG4 regulation in two mouse models of DKD, that is $\mathrm{NNOS}^{-/-} ; \mathrm{db} / \mathrm{db}$ mice and $d b / d b$ mice as compared to two different groups of nondiabetic control mice, that is, $\mathrm{NOS}^{-/-}$mice and $d b /+$ mice.

In all adipose tissue depots investigated, that is BAT, VAT and SAT, Nrg4 mRNA expression was significantly reduced in 24-week-old mice with DKD. The lowest expression of $\mathrm{Nrg} 4$ was observed in mice with severe DKD, that is $\mathrm{eNOS}^{-/-} ; \mathrm{db} / \mathrm{db}$ mice, in BAT and SAT (Fig. 1A and $\mathrm{C})$, as well as in mice with mild $\mathrm{DKD}$, that is $d b / d b$ mice, in VAT (Fig. 1B). In contrast, Nrg4 mRNA expression in the liver was significantly increased in mice with DKD as compared to two groups of non-diabetic controls (Fig. 1D), whereas Nrg4 mRNA expression in the kidney was unaltered (Fig. 1E).

Urinary ACR was increased in mice with severe DKD, that is, $\mathrm{eNOS}^{-/-} ; d b / d b$ mice (Fig. 1F).

In the kidneys, mErbb4 mRNA expression was significantly higher in $\mathrm{eNOS}^{-/-}$mice as compared to $d b / d b$ mice (Supplementary Fig. 1, see section on supplementary data given at the end of this article). In contrast, renal mErbb4 mRNA expression was not different with control mice, that is, $d b /+$ mice, compared to mice with severe $\mathrm{DKD}$, that is $\mathrm{NOOS}^{-/-} ; d b / d b$ mice (Supplementary Fig. 1).

\section{Effect of the uremic toxin indoxyl sulfate on $\mathrm{Nrg} 4$ mRNA expression in murine brown adipocytes, 3T3-L1 adipocytes and AML12 hepatocytes in vitro}

Treatment of murine brown adipocytes (Fig. 2A), murine 3T3-L1 white adipocytes (Fig. 2B), as well as murine AML12 hepatocytes (Fig. 2C), with the uremic toxin indoxyl sulfate for $24 \mathrm{~h}$ did not significantly alter the mRNA expression of $\mathrm{Nrg} 4$ as compared to control cells treated with potassium sulfate.

Table 3 Univariate correlations of several BAT-secreted adipokines and markers of BAT function with serum neuregulin 4. Univariate correlations of serum levels of the respective adipokines with each other in the total study population ( $n=120) . r$ and $P$ values are given.

\begin{tabular}{|c|c|c|}
\hline & & Neuregulin 4 \\
\hline \multirow[t]{2}{*}{ Neuregulin $4(\mu g / L)$} & $r$ & - \\
\hline & $P$ & - \\
\hline \multirow[t]{2}{*}{ Irisin ( $\mu g / L)$} & $r$ & 0.261 \\
\hline & $P$ & 0.004 \\
\hline \multirow[t]{2}{*}{ Angptl8 ( $\mu g / L)$} & $r$ & 0.125 \\
\hline & $P$ & 0.174 \\
\hline \multirow[t]{2}{*}{ Adiponectin (mg/L) } & $r$ & 0.220 \\
\hline & $P$ & 0.016 \\
\hline \multirow[t]{2}{*}{ FGF21 (ng/L) } & $r$ & -0.266 \\
\hline & $P$ & 0.003 \\
\hline
\end{tabular}
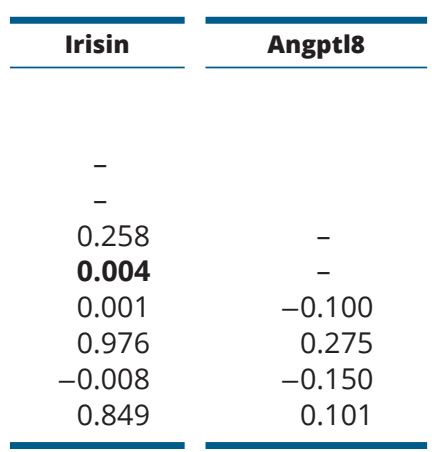

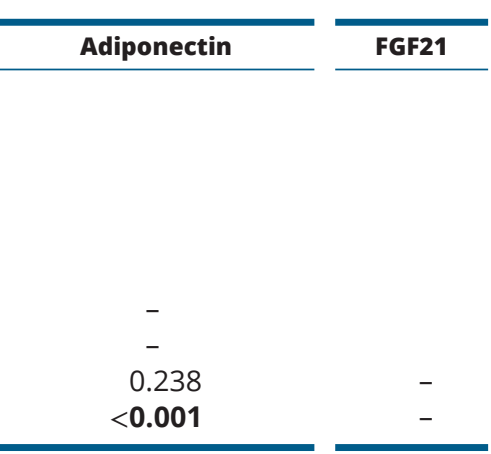

Bold values indicate significant correlation as assessed by Spearman's correlation method.

Angptl8, angiopoietin-like protein 8; BAT, brown adipose tissue; FGF21, fibroblast growth factor 21. 

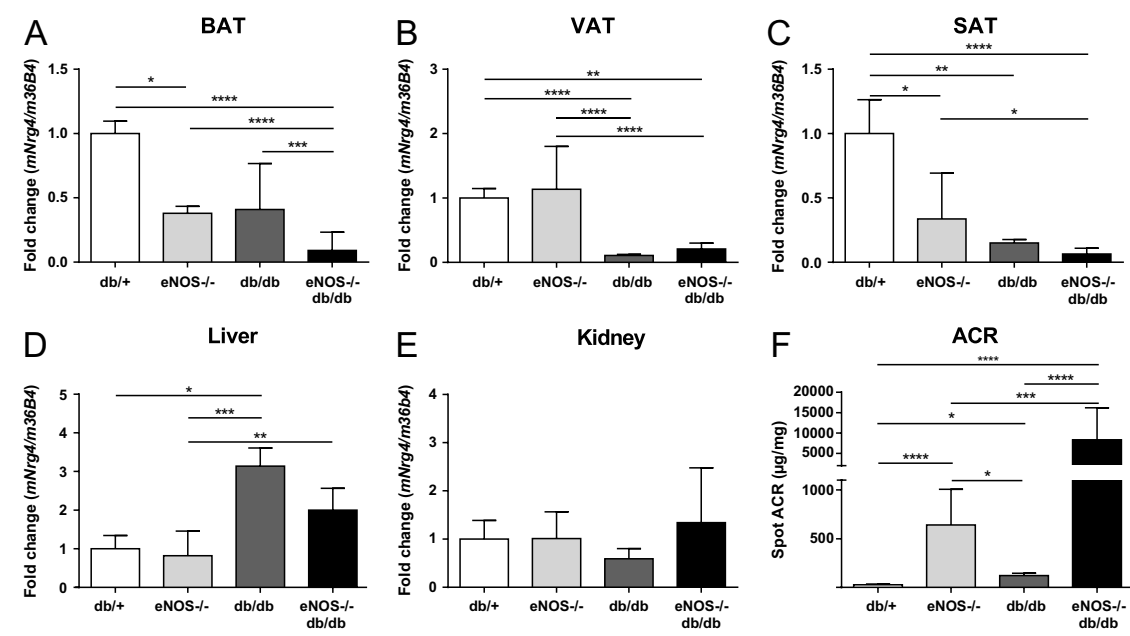

\section{Figure 1}

Neuregulin 4 regulation in 24-week-old mice with severe DKD $\left(e \mathrm{NOS}^{-1-} ; d b / d b\right.$; black bars) and mild DKD ( $d b / d b$; dark grey bars) as compared to two groups of non-diabetic control mice, i.e. eNOS-/mice (light grey bars) and $d b /+$ mice (white bars). (A, B, C, D and E) Nrg4 mRNA expression normalized to $36 B 4$ in (A) brown adipose tissue (BAT), (B) visceral adipose tissue (VAT), (C) subcutaneous adipose tissue (SAT), (D) liver, as well as (E) kidney. (F) Urinary albumin-creatinine ratio (ACR) in spot urine. Results are shown as means \pm standard deviation. $P$ values as assessed by one-way ANOVA with Tukey's multiple comparisons test. $n \geq 3$ per group. *Indicates $P<0.05$, $\star \star P<0.01 ; * \star * P<0.001, * \star \star * P<0.0001$.

of NRG4 (6) is significantly downregulated in mice with DKD as compared to non-diabetic control mice in all adipose tissue depots, i.e. BAT, VAT and SAT. Based on our results, uremic and/or metabolic disturbances observed in CKD and DKD might influence Nrg4 expression in renal dysfunction on a transcriptional level similar to irisin (27). We, therefore, have treated murine brown and white adipocytes, as well as murine hepatocytes, with the uremic toxin indoxyl sulfate. Here, the uremic toxin indoxyl sulfate does not alter the mRNA expression of $\mathrm{Nrg} 4$ in all three cell types suggesting that this major uremic toxin is not responsible for reduced circulating NRG4 in ESKD. It should be noted that in addition to indoxyl sulfate other uremic toxins are increased in CKD (reviewed in (28)) potentially contributing to the observed effects. Thus, p-cresyl sulfate, another proteinbound uremic toxin, directly induces cardiometabolic effects, i.e. insulin resistance in CKD (29). Further studies, therefore, are needed to investigate whether NRG4 has direct and causal effects on renal function and to identify the pathophysiological mechanisms of NRG4 regulation in CKD. It has to be pointed out that Nugroho and coworkers have convincingly demonstrated that NRG4 directly induces angiogenesis and angiogenic function in adipose tissue thereby ameliorating adipose tissue hypoxia $(30,31)$. Furthermore, ERBB4 signaling is involved in the activation of eNOS in cardiac myocytes (32). Thus, future studies also need to investigate whether vascular effects of NRG4 directly contribute to the development of CKD. Importantly, our translational findings suggest 

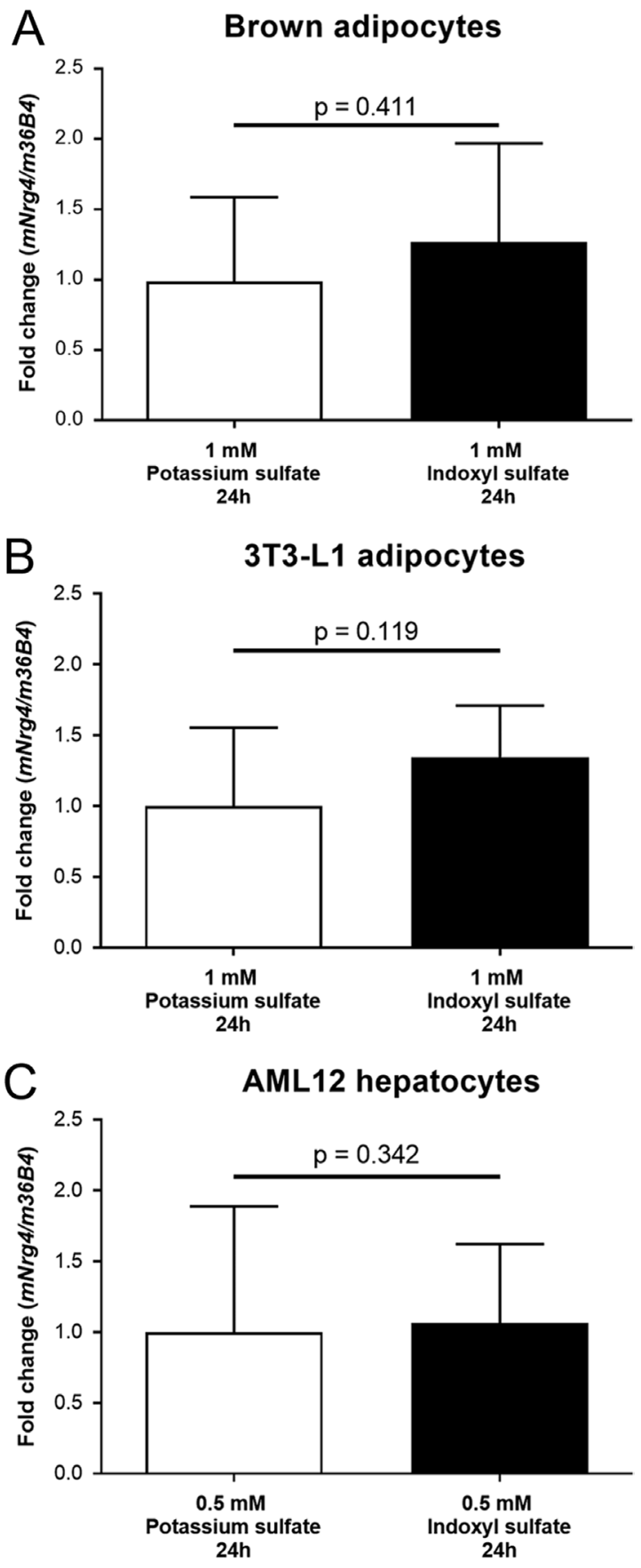

\section{Figure 2}

Neuregulin 4 regulation in (A) differentiated, immortalized murine brown adipocytes, (B) murine 3T3-L1 white adipocytes and $(C)$ murine AML12 hepatocytes after treatment with $1 \mathrm{mM}$ ( $A$ and $B$ ) or $0.5 \mathrm{mM}(C)$ indoxyl sulfate for $24 \mathrm{~h}$ as compared to control cells treated with $1 \mathrm{mM}$ (A and B) or $0.5 \mathrm{mM}(\mathrm{C})$ potassium sulfate for $24 \mathrm{~h}$. The mRNA expression of $\mathrm{Nrg} 4$ normalized to $36 B 4$ is depicted. Results are shown as means \pm standard deviation. $P$ value as assessed by Student's $t$ test. $n \geq 5$ per group. that markers of renal function, for example, creatinine or eGFR, should be included in all future studies on Nrg4 physiology.

Besides renal function, NRG4 is independently and positively associated with HDL cholesterol, as well as negatively correlated to TG, in our cohort. Interestingly, these results are virtually the same when patients with ESKD and subjects without CKD are analyzed separately (data not shown). When the association between NRG4 with HDL cholesterol and TG are investigated in the four subgroups separately, correlations remain significant only in patients with T2DM (data not shown). These data suggest a beneficial metabolic regulation of NRG4 in patients with ESKD. In accordance with this hypothesis, Wang et al. demonstrate that mice with a transgenic overexpression of NRG4 show lower TG levels in both the liver and plasma (6). Furthermore, Yan and coworkers have shown an independent and positive association between NRG4 and HDL cholesterol in 311 Chinese patients with newly diagnosed T2DM supporting our subgroup analyses (33). Thus, future studies need to investigate whether NRG4 causally regulates plasma lipoprotein particles. Furthermore, NRG4 is positively correlated with irisin and adiponectin in our cohort. For both adipokines, a beneficial correlation with markers of dyslipidemia has been reported previously $(34,35)$. The negative association of NRG4 with FGF21 might also be mediated by the well-known upregulation of FGF21 in cardiometabolic disease states (36).

It is interesting to note that in our cohort, patients with T2DM have unaltered NRG4 serum levels as compared to non-diabetic controls. This is in contrast to previous data from our group demonstrating reduced NRG4 levels in women with gestational diabetes mellitus as compared to controls (37). Furthermore, data on circulating levels of Nrg4 in patients with T2DM are inconsistent, so far and some studies suggest decreased (38) or increased (39) NRG4 levels in patients with T2DM as compared to controls. Mechanistically, Wang and coworkers elegantly demonstrate that mice with a transgenic overexpression of NRG4 have had an improved insulin sensitivity as compared to controls (6). In more detail, the adipokine exerts its beneficial metabolic effects by binding to the ERBB4 receptor (6). Zeng and coworkers convincingly demonstrate that heart rescued ERBB4 deletion mice (Erbb $4^{-/-} h t^{+}$) have increased HOMA-IR levels (40). Furthermore, treatment of epididymal adipocytes from WT mice with recombinant NRG4 has increased glucose uptake to levels comparable to insulin treatment, whereas there is no effect of NRG4 in adipocytes isolated from Erbb4 $4^{-/} h t^{+}$mice (40). 
It is worth noting that we have shown a beneficial and negative association of the adipokine with markers of insulin resistance, for example, HOMA-IR, in our cohort supporting the rodent data from Zeng et al. (40). Based on our data in mice with DKD, there is no similar pattern of renal Erbb4 mRNA expression as compared to Nrg4 expression in adipose tissue depots. Thus, a disturbed ERBB4 regulation does not seem to be causally involved in the observed renal associations.

We have further found a positive association of NRG4 with systolic blood pressure in our human cohort. This is in contrast to data from Cai and coworkers showing decreased NRG4 levels in patients with hypertension as compared to normotensive controls (41). However, statistical significance has been lost after adjustment for confounders in their Chinese study (41). Thus, future studies need to assess the causal role of NRG4 on hypertension in human metabolic disease states.

Taken together, circulating NRG4 is independently associated with a preserved renal function and mRNA expression of $\mathrm{Nrg} 4$ is reduced in adipose tissue depots of mice with DKD. The BAT-secreted adipokine is further associated with a beneficial glucose and lipid profile supporting NRG4 as potential treatment target in metabolic and renal disease states.

\section{Supplementary data}

This is linked to the online version of the paper at https://doi.org/10.1530/ EJE-19-0017.

\section{Declaration of interest}

The authors declare that there is no conflict of interest that could be perceived as prejudicing the impartiality of this study.

\section{Funding}

This work was supported by the Deutsche Forschungsgemeinschaft (DFG; German Research Foundation - Projektnummer 209933838 - SFB 1052/2, B1 to M B, B4 to N K and (6 to M F) and by the Federal Ministry of Education and Research (BMBF), Germany, FKZ: $01 E 01501$ (IFB AdiposityDiseases, project K6a-87). TE was supported by the Federal Ministry of Education and Research (BMBF), Germany, FKZ: $01 E 01501$ (IFB AdiposityDiseases, Postdoctoral program), as well as by a Novo Nordisk postdoctoral fellowship run in partnership with Karolinska Institutet, Stockholm, Sweden. A H was supported by a grant from the Nachwuchsförderprogramm of the Medical Faculty, University of Leipzig.

\section{Author contribution statement}

$\mathrm{S} \mathrm{K}, \mathrm{A} \mathrm{H}, \mathrm{M} \mathrm{F}$ and T E wrote the manuscript and researched data. N K, A F, $H K, M N, S P$ and $A B$ researched data and reviewed/edited the manuscript. M B, M-Z Z, R C H and M S contributed to the discussion and reviewed/ edited the manuscript. Guarantor: Dr Thomas Ebert is the guarantor of this work and, as such, had full access to all the data in the study and takes responsibility for the integrity of the data and the accuracy of the data analysis. S K, A H, M F and T E equally contributed to this work.

\section{References}

1 Lozano R, Naghavi M, Foreman K, Lim S, Shibuya K, Aboyans V, Abraham J, Adair T, Aggarwal R, Ahn SY et al. Global and regional mortality from 235 causes of death for 20 age groups in 1990 and 2010: a systematic analysis for the Global Burden of Disease Study 2010. Lancet 2012380 2095-2128. (https://doi.org/10.1016/S0140-6736(12)61728-0)

2 Chang AR, Grams ME, Ballew SH, Bilo H, Correa A, Evans M, Gutierrez OM, Hosseinpanah F, Iseki K, Kenealy T et al. Adiposity and risk of decline in glomerular filtration rate: meta-analysis of individual participant data in a global consortium. BMJ 2019364 k5301. (https://doi.org/10.1136/bmj.k5301)

3 Shulman A, Peltonen M, Sjöström CD, Andersson-Assarsson JC, Taube M, Sjöholm K, le Roux CW, Carlsson LMS \& Svensson PA Incidence of end-stage renal disease following bariatric surgery in the Swedish obese subjects study. International Journal of Obesity 201842 964-973. (https://doi.org/10.1038/s41366-018-0045-x)

4 Cypess AM \& Kahn CR. Brown fat as a therapy for obesity and diabetes. Current Opinion in Endocrinology, Diabetes, and Obesity 2010 17 143-149. (https://doi.org/10.1097/MED.0b013e328337a81f) 5 Villarroya F, Cereijo R, Villarroya J \& Giralt M. Brown adipose tissue as a secretory organ. Nature Reviews: Endocrinology 201713 26-35. (https://doi.org/10.1038/nrendo.2016.136)

6 Wang GX, Zhao XY, Meng ZX, Kern M, Dietrich A, Chen Z, Cozacov Z, Zhou D, Okunade AL, Su X et al. The brown fat-enriched secreted factor Nrg4 preserves metabolic homeostasis through attenuation of hepatic lipogenesis. Nature Medicine 201420 1436-1443. (https://doi.org/10.1038/nm.3713)

7 Ebert T, Kralisch S, Hoffmann A, Bachmann A, Lössner U, Kratzsch J, Blüher M, Stumvoll M, Tönjes A \& Fasshauer M. Circulating angiopoietinlike protein 8 is independently associated with fasting plasma glucose and type 2 diabetes mellitus. Journal of Clinical Endocrinology and Metabolism 201499 E2510-E2517. (https://doi.org/10.1210/jc.2013-4349)

8 Ziegelmeier M, Bachmann A, Seeger J, Lossner U, Kratzsch J, Blüher M, Stumvoll M \& Fasshauer M. Serum levels of adipokine retinol-binding protein-4 in relation to renal function. Diabetes Care 200730 2588-2592. (https://doi.org/10.2337/dc07-0275)

9 Stein S, Bachmann A, Lossner U, Kratzsch J, Bluher M, Stumvoll M \& Fasshauer M. Serum levels of the adipokine FGF21 depend on renal function. Diabetes Care 200932 126-128. (https://doi.org/10.2337/ dc08-1054)

10 Kralisch S, Hoffmann A, Klöting N, Bachmann A, Kratzsch J, Blüher M, Zhang MZ, Harris RC, Stumvoll M, Fasshauer M et al. The novel adipokine/hepatokine fetuin B in severe human and murine diabetic kidney disease. Diabetes and Metabolism 201743 465-468. (https://doi.org/10.1016/j.diabet.2017.01.005)

11 Levey AS, Stevens LA, Schmid CH, Zhang YL, Castro AF, Feldman HI, Kusek JW, Eggers P, Van Lente F, Greene T et al. A new equation to estimate glomerular filtration rate. Annals of Internal Medicine $2009 \mathbf{1 5 0}$ 604-612. (https://doi.org/10.7326/0003-4819-150-9-200905050-00006)

12 American Diabetes Association. Diagnosis and classification of diabetes mellitus. Diabetes Care 201236 S67-S74. (https://doi. org/10.2337/dc13-S067)

13 Matthews DR, Hosker JP, Rudenski AS, Naylor BA, Treacher DF \& Turner RC. Homeostasis model assessment: insulin resistance and beta-cell function from fasting plasma glucose and insulin concentrations in man. Diabetologia 198528 412-419. (https://doi. org/10.1007/BF00280883)

14 Zhao HJ, Wang S, Cheng H, Zhang MZ, Takahashi T, Fogo AB, Breyer MD \& Harris RC. Endothelial nitric oxide synthase deficiency produces accelerated nephropathy in diabetic mice. Journal of the American Society of Nephrology 200617 2664-2669. (https://doi. org/10.1681/ASN.2006070798)

15 Sharma K, McCue P \& Dunn SR. Diabetic kidney disease in the db/ db mouse. American Journal of Physiology: Renal Physiology 2003284 F1138-F1144. (https://doi.org/10.1152/ajprenal.00315.2002) 
16 Ebert T, Kralisch S, Klöting N, Hoffmann A, Blüher M, Zhang MZ, Harris RC, Stumvoll M \& Fasshauer M. Circulating progranulin but not renal progranulin expression is increased in renal dysfunction. Kidney International 201588 1197-1198. (https://doi.org/10.1038/ ki.2015.266)

17 Kralisch S, Hoffmann A, Klöting N, Bachmann A, Kratzsch J, Stolzenburg JU, Dietel A, Beige J, Anders M, Bast I et al. FSTL3 is increased in renal dysfunction. Nephrology, Dialysis, Transplantation 201732 1637-1644. (https://doi.org/10.1093/ndt/gfw472)

18 Ebert T, Focke D, Petroff D, Wurst U, Richter J, Bachmann A, Lössner U, Kralisch S, Kratzsch J, Beige J et al. Serum levels of the myokine irisin in relation to metabolic and renal function. European Journal of Endocrinology 2014170 501-506. (https://doi.org/10.1530/EJE-13-1053)

19 Klein J, Fasshauer M, Ito M, Lowell BB, Benito M \& Kahn CR. $\beta 3$-Adrenergic stimulation differentially inhibits insulin signaling and decreases insulin-induced glucose uptake in brown adipocytes. Journal of Biological Chemistry 1999274 34795-34802. (https://doi. org/10.1074/jbc.274.49.34795)

20 Stockler-Pinto MB, Saldanha JF, Yi D, Mafra D, Fouque D \& Soulage CO. The uremic toxin indoxyl sulfate exacerbates reactive oxygen species production and inflammation in 3T3-L1 adipose cells. Free Radical Research 201650 337-344. (https://doi.org/10.3109/1071 5762.2015.1125996)

21 Cohen G, Glorieux G, Thornalley P, Schepers E, Meert N, Jankowski J, Jankowski V, Argiles A, Anderstam B, Brunet P et al. Review on uraemic toxins III: recommendations for handling uraemic retention solutes in vitro towards a standardized approach for research on uraemia. Nephrology, Dialysis, Transplantation 200722 3381-3390. (https://doi.org/10.1093/ndt/gfm210)

22 Merabet E, Dagogo-Jack S, Coyne DW, Klein S, Santiago JV, Hmiel SP \& Landt M. Increased plasma leptin concentration in end-stage renal disease. Journal of Clinical Endocrinology and Metabolism 199782 847-850. (https://doi.org/10.1210/jcem.82.3.3817)

23 Zoccali C, Mallamaci F, Tripepi G, Benedetto FA, Cutrupi S, Parlongo S, Malatino LS, Bonanno G, Seminara G, Rapisarda F et al. Adiponectin, metabolic risk factors, and cardiovascular events among patients with end-stage renal disease. Journal of the American Society of Nephrology 200213 134-141.

24 Richter J, Focke D, Ebert T, Kovacs P, Bachmann A, Lössner U, Kralisch S, Kratzsch J, Beige J, Anders M et al. Serum levels of the adipokine progranulin depend on renal function. Diabetes Care 2013 36 410-414. (https://doi.org/10.2337/dc12-0220)

25 Ebert T, Hopf LM, Wurst U, Bachmann A, Kralisch S, Lössner U, Platz M, Kratzsch J, Stolzenburg JU, Dietel A et al. Circulating adipocyte fatty acid binding protein is increased in chronic and acute renal dysfunction. Nutrition, Metabolism, and Cardiovascular Diseases 201424 1027-1034. (https://doi.org/10.1016/j.numecd.2014.03.006)

26 Hindricks J, Ebert T, Bachmann A, Kralisch S, Lössner U, Kratzsch J, Stolzenburg JU, Dietel A, Beige J, Anders M et al. Serum levels of fibroblast growth factor-21 are increased in chronic and acute renal dysfunction. Clinical Endocrinology 201480 918-924. (https://doi. org/10.1111/cen.12380)

27 Wen MS, Wang CY, Lin SL \& Hung KC. Decrease in irisin in patients with chronic kidney disease. PLoS ONE 20138 e64025. (https://doi. org/10.1371/journal.pone.0064025)

28 Duranton F, Cohen G, Smet RD, Rodriguez M, Jankowski J, Vanholder R \& Argiles A. Group on behalf of the EUTW. Normal and pathologic concentrations of uremic toxins. Journal of the American Society of Nephrology 201223 1258-1270. (https://doi.org/10.1681/ ASN.2011121175)
29 Koppe L, Pillon NJ, Vella RE, Croze ML, Pelletier CC, Chambert S, Massy Z, Glorieux G, Vanholder R, Dugenet Y et al. p-cresyl sulfate promotes insulin resistance associated with CKD. Journal of the American Society of Nephrology 201324 88-99. (https://doi. org/10.1681/ASN.2012050503)

30 Nugroho DB, Ikeda K, Barinda AJ, Wardhana DA, Yagi K, Miyata K, Oike Y, Hirata KI \& Emoto N. Neuregulin-4 is an angiogenic factor that is critically involved in the maintenance of adipose tissue vasculature. Biochemical and Biophysical Research Communications 2018503 378-384. (https://doi.org/10.1016/j.bbrc.2018.06.043)

31 Nugroho DB, Ikeda K, Kajimoto K, Hirata KI \& Emoto N. Activation of neuregulin-4 in adipocytes improves metabolic health by enhancing adipose tissue angiogenesis. Biochemical and Biophysical Research Communications $2018 \mathbf{5 0 4}$ 427-433. (https://doi. org/10.1016/j.bbrc.2018.08.197)

32 Feron O, Zhao YY \& Kelly RA. The ins and outs of caveolar signaling: $\mathrm{m} 2$ muscarinic cholinergic receptors and eNOS activation versus neuregulin and ErbB4 signaling in cardiac myocytesa. Annals of the New York Academy of Sciences 1999874 11-19. (https://doi. org/10.1111/j.1749-6632.1999.tb09220.x)

33 Yan P, Xu Y, Wan Q, Feng J, Li H, Yang J, Zhong H \& Zhang Z. Plasma neuregulin 4 levels are associated with metabolic syndrome in patients newly diagnosed with type 2 diabetes mellitus. Disease Markers 20182018 6974191. (https://doi.org/10.1155/2018/6974191)

34 Ebert T, Kralisch S, Wurst U, Scholz M, Stumvoll M, Kovacs P, Fasshauer M \& Tönjes A. Association of metabolic parameters and rs726344 in FNDC5 with serum irisin concentrations. International Journal of Obesity 201640 260-265. (https://doi.org/10.1038/ ijo.2015.157)

35 Ebert T, Gebhardt C, Scholz M, Wohland T, Schleinitz D, Fasshauer M, Blüher M, Stumvoll M, Kovacs P \& Tönjes A. Relationship between 12 adipocytokines and distinct components of the metabolic syndrome. Journal of Clinical Endocrinology and Metabolism 2018103 1015-1023. (https://doi.org/10.1210/jc.2017-02085)

36 Zhang X, Yeung DCY, Karpisek M, Stejskal D, Zhou ZG, Liu F, Wong RLC, Chow WS, Tso AWK, Lam KSL et al. Serum FGF21 levels are increased in obesity and are independently associated with the metabolic syndrome in humans. Diabetes 200857 1246-1253. (https://doi.org/10.2337/db07-1476)

37 Kralisch S, Hoffmann A, Kratzsch J, Blüher M, Stumvoll M, Fasshauer M \& Ebert T. The brown-fat-secreted adipokine neuregulin 4 is decreased in gestational diabetes mellitus. Diabetes and Metabolism 201844 150-154. (https://doi.org/10.1016/j.diabet.2017.06.001)

38 Zhang L, Fu Y, Zhou N, Cheng X \& Chen C. Circulating neuregulin 4 concentrations in patients with newly diagnosed type 2 diabetes: a cross-sectional study. Endocrine 201757 535-538. (https://doi. org/10.1007/s12020-017-1324-3)

39 Kang YE, Kim JM, Choung S, Joung KH, Lee JH, Kim HJ \& Ku BJ. Comparison of serum neuregulin 4 (Nrg4) levels in adults with newly diagnosed type 2 diabetes mellitus and controls without diabetes. Diabetes Research and Clinical Practice 2016117 1-3. (https://doi. org/10.1016/j.diabres.2016.04.007)

40 Zeng F, Wang Y, Kloepfer LA, Wang S \& Harris RC. ErbB4 deletion predisposes to development of metabolic syndrome in mice. American Journal of Physiology: Endocrinology and Metabolism 2018315 E583-E593. (https://doi.org/10.1152/ajpendo.00166.2018)

41 Cai C, Lin M, Xu Y, Li X, Yang S \& Zhang H. Association of circulating neuregulin 4 with metabolic syndrome in obese adults: a cross-sectional study. BMC Medicine 201614165 . (https://doi. org/10.1186/s12916-016-0703-6)

Received 8 January $\backslash 2019$

Revised version received 16 May 2019

Accepted 31 May 2019 